\title{
Recurrence of Graves' Disease (a Th1-type Cytokine Disease) Following SARS-CoV-2 mRNA Vaccine Administration: A Simple Coincidence?
}

\author{
Guillaume Pierman, Etienne Delgrange, Corinne Jonas \\ Department of Endocrinology, Centre Hospitalier Universitaire de Mont-Godinne, Yvoir, Belgium
}

Received: 29/07/2021

Accepted: 01/08/2021

Published: 02/09/2021

\begin{abstract}
How to cite this article: Pierman G, Delgrange E, Jonas C. Recurrence of Graves' disease (a Th1-type cytokine disease) following SARS-CoV-2 mRNA Vaccine administration: a simple coincidence? EJCRIM 2021;8: doi:10.12890/2021_002807.
\end{abstract}

Conflicts of Interests: The authors declare there are no competing interests.

This article is licensed under a Commons Attribution Non-Commercial 4.0 License

\section{ABSTRACT}

Graves' disease is the most frequent cause of hyperthyroidism in young women. This auto-immune disease is due to the production of class $1 \mathrm{lgG}$ stimulating the TSH receptor. These antibodies are produced secondary to a Th1 immune response in which interferon gamma plays a key role. Vaccination is ongoing worldwide against SARS-CoV-2 and some of the vaccines include mRNA which seems to stimulate the Th1 immune response. Here, we report a case of recurrence of hyperthyroidism due to Graves' disease following mRNA vaccination and discuss the possible implicated mechanism. This observation argues for a systematic study of a population of patients with previous Graves' disease in order to assess the risk of recurrence following vaccination.

\section{LEARNING POINTS}

- Graves' disease is a Th1-mediated immune disease in which interferon gamma plays a key role.

- The recurrence of hyperthyroidism due to Grave's disease should be monitored in patients exposed to risk factors.

\section{KEYWORDS}

Hyperthyroidism, Graves' disease, vaccine, SARS-CoV-2

\section{INTRODUCTION}

Vaccination is ongoing worldwide against SARS-CoV-2 and for the first time, some of the vaccines include mRNA. Recently, several cases of myocarditis were reported after mRNA vaccination, which should prompt us to watch out for other potential immune side effects of these new generation vaccines.

\section{CASE DESCRIPTION}

We describe the case of a-34-year-old woman, already known for Graves' disease diagnosed in August 2010 during a second pregnancy. She had been treated with propylthiouracil for a short time before she gave birth in March 2011. The hyperthyroidism recurred after pregnancy and the patient then received long-term treatment with thiamazole until remission of the Grave's disease in June 2014. Thereafter, the patient remained completely symptom-free until May 2021. Apart her Graves' disease, she is in good health and a non-smoker.

On 12 May, she received the first dose of the mRNA BNT162b2 COVID-19 vaccine (Pfizer/BioNTech). About 10 days later, she developed swelling of the eyelids associated with distal tremor, sweating, thermophobia, dyspnoea on exertion and a weight loss of $4 \mathrm{~kg}$. She received the second dose of the vaccine on 16 June. 
Due to worsening symptoms after the second dose, a blood test was conducted on 21 June by her general practitioner and showed the following values: thyroid stimulating hormone below $0.01 \mathrm{mU} / \mathrm{l}(0.4-2.75 \mathrm{mU} / \mathrm{l})$, free T4 $2.54 \mathrm{ng} / \mathrm{dl}$ (0.75-1.6 ng/dl), free T3 22.09 pmol/l (3-6.5 pmol/I) and anti-TSH receptor antibodies greater than $40 \mathrm{IU} / \mathrm{I}(<0.55 \mathrm{IU} / \mathrm{I})$. The remaining laboratory test results were in the normal range. We saw the patient for an endocrinology consultation on 23 June. Physical examination revealed diffuse goitre, eyelid oedema, clammy skin, Achilles' tendon hyperreflexia and distal tremors. We confirmed recurrence of Graves' disease. Treatment with thiamazole 20 mg twice a day was initiated.

\section{DISCUSSION}

Graves' disease is the most frequent cause of hyperthyroidism in young women and is due to stimulation of the TSH receptor by antibodies. Graves' disease usually occurs when predisposing factors (genetic susceptibility) meet precipitating factors (infection, smoking, postpartum, drugs, etc.). We describe a case of Graves' disease recurrence after vaccination against COVID-19 and wonder if the vaccine should be considered a potential trigger for Graves' disease relapse?

In a recent case report [1], two cases of new-onset Grave's disease were described 2 and 3 days, respectively, after the first injection of the mRNA BNT162b2 COVID-19 vaccine. Due to the very short delay between vaccination and the onset of symptoms, the disease might have preceded vaccination.

In a large study on the safety of the HPV4 vaccine, the time interval chosen as the 'exposure risk window' after administration of the vaccine was 7-60 days ${ }^{[2]}$, which seems more logical in order to allow time for the immune mechanisms to respond. In this HPV study, there was no statistically significant association between the HPV4 vaccine and Grave's disease.

Other drugs have also been associated with the onset of new Graves' disease. This is especially the case for a monoclonal antibody called alemtuzumab when used for the treatment of multiple sclerosis (a Th1-mediated disease) ${ }^{[3]}$. This antibody provokes depletion of the T-cell population and leads to the onset of Grave's disease in a third of patients. This is interesting because although the immune mechanisms underlying Graves' disease are not fully understood, it is known to be mainly a Th1-mediated disease ${ }^{[4]}$. Interferon gamma plays a key role by promoting the presentation of thyroid antigen via the HLA class II and then the production of class 1 IgG stimulating the TSH receptor. The same immune mechanisms are probably at work with the mRNA vaccine. Indeed, during a phase I/II study, it has been shown that the immune response to the vaccine candidate mRNA BNT162b1 was from a Th1 type with production of interferon gamma ${ }^{[5]}$. Therefore, modification of the cytokine environment induced by the vaccine could lead to modification of the T-cell repertoire in favour of a Th1 population and then to new production of antibodies stimulating the TSH receptor, resulting in a relapse of hyperthyroidism.

\section{CONCLUSION}

We report a case of recurrence of hyperthyroidism due to Graves' disease following administration of an mRNA COVID-19 vaccine. It is not possible to establish a link between the two events and the benefits of COVID-19 vaccination are obviously not in question. Vaccination must be the priority in the fight against COVID-19. A systematic study of a population of patients with previous Graves' disease would be necessary in order to assess the risk of recurrence following vaccination. If a link was shown, it would allow us to better understand the pathophysiology of Graves' disease.

\section{REFERENCES}

1. Vera-Lastra O, Ordinola Navarro A, Pilar Cruz Domiguez M, Medina G, Sanchez Valadez Ti, Jara LJ. Two cases of Grave's disease following SARS-CoV-2 vaccination: an autoimmune/inflammatory syndrome induced by adjuvants. Thyroid 2021 May 3. doi: 10.1089/thy.2021.0142 (online ahead of print).

2. Liu EY, Smith LM, Ellis AK, Whitaker H, Law B, Kwong JC, et al. Quadrivalent human papillomavirus vaccination in girls and the risk of autoimmune disorders: the Ontario grade 8 HPV vaccine cohort study. CMAJ 2018;190(21):E648-E695. doi: 10.1503/cmaj.170871

3. Coles AJ, Wing M, Smith S, Coraddu F, Greer S, Taylor C, et al. Pulsed monoclonal antibody treatment and autoimmune thyroid disease in multiple sclerosis. Lancet 1999;354:1691. doi: 10.1016/S0140-6736(99)02429-0

4. Rapoport B, McLachlan SM. Graves' hyperthyroidism is antibody-mediated but is predominantly a Th1-type cytokine disease. J Clin Endocrinol Metab 2014;99:4060. doi: 10.1210/jc.2014-3011

5. Sahin U, Muik A, Derhovanessian E, Vogler I, Kranz LM, Vormehr M, et al. Covid-19 vaccine BNT162b1 elicits human antibody and Th1 T cell responses. Nature 2020;586(7830):594-599. doi: 10.1038/s41586-020-2814-7 